\title{
CONSERVAÇÃO DAS PROPRIEDADES TENSOATIVAS ENTRE OS BIOSSURFACTANTES PRODUZIDOS POR Candida sphaerica E Candida lipolytica
}

\author{
P. P. F. BRASILEIRO ${ }^{1,2}$, J. G. M. BRITO ${ }^{1}$, B. G. de FREITAS ${ }^{1}$, H. S. AMORIM ${ }^{1}$, I. N. S. \\ FERREIRA $^{1,2}$, J. M. de LUNA ${ }^{1,2}$, R. D. RUFINO ${ }^{1,2}$, L. A. SARUBBO ${ }^{1,2}$ e V. A. dos SANTOS SA, $^{1,2}$ \\ ${ }^{1}$ Universidade Católica de Pernambuco (UNICAP), Centro de Ciências e Tecnologia (CCT) \\ ${ }^{2}$ Centro de Gestão de Tecnologia e Inovação (CGTI) \\ E-mail para contato: ppfbrasileiro@hotmail.com
}

\begin{abstract}
RESUMO - Derramamentos petrolíferos são frequentes e a remediação química eleva a toxicidade nas áreas marinhas contaminadas. No intuito de controlar essa mistura de hidrocarbonetos, as leveduras Candida lipolytica e Candida sphaerica foram utilizadas em meios de produção específicos para a síntese de dois compostos biodegradáveis e estáveis nas condições ambientais: os biossurfactantes. Após a adição do conservante sorbato de potássio, foram analisadas as propriedades tensoativas durante $120 \mathrm{~d}$, isoladamente alterando-se o $\mathrm{pH}$ ou a salinidade ou aquecendo-se para as escolhas das melhores condições de aplicação de cada biossurfactante. Dessas seleções, contrapuseram-se as mais eficientes e uniformes propriedades, obtendo-se, no biossurfactante de $C$. sphaerica, mínima tensão superficial de $22,45 \mathrm{mN} / \mathrm{m}$ e máximas emulsão de $94,1 \%$ e dispersão de $73,3 \%$. Este surfactante microbiano foi, logo, o mais eficiente no controle de petroderivados em água marinha durante a conservação por $120 \mathrm{~d}$.
\end{abstract}

\section{INTRODUÇÃO}

Em 2010, um dos maiores derramamentos de petróleo da história, ocorrido no Golfo do México, foi um alerta aos pesquisadores de todo o mundo da ausência de práticas seguras na sucção desse contaminante marinho. Nesse ano, cerca de 800.000.000 L de petróleo foram despejados em pleno oceano, alastrando um desequilíbrio na fauna e flora marinhas por $1,5 \mathrm{~km}$ de profundidade. $\mathrm{Na}$ tentativa de remediar a área, cientistas propuseram aplicar $3.000 .000 \mathrm{~L}$ de compostos conhecidos como surfactantes químicos para tentar controlar a grande mancha formada. A ideia, no entanto, foi uma propagação do erro devido ao acúmulo da toxicidade causado pelo acréscimo de substâncias também petroderivadas. Ademais, esse acidente foi divulgado em diversos meios de comunicação não pelo motivo de ser o maior da história, todavia por ser o acontecimento em que houve o maior gasto na recuperação incompleta da área degradada e nas multas ambientais (TANSEL, 2014).

A engenharia química apresenta-se como resolutiva nesses imbróglios de contaminação porque engloba várias áreas da ciência como a microbiologia, a qual utiliza micro-organismos com potencial biotecnológico para degradar ou controlar compostos poluentes no solo ou no mar através da 


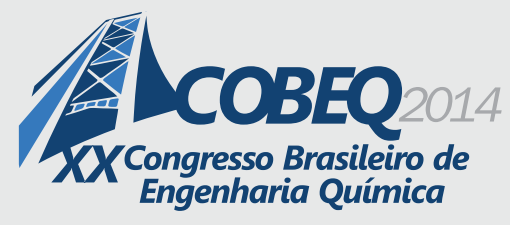

19 a 22 de outubro de 2014

Florianópolis/SC

biorremediação. Essa técnica é constituída por três práticas: bioaumentação, bioestimulação e biossolubilização. As duas primeiras referem-se, respectivamente, ao incremento de microorganismos e nutrientes específicos em uma área contaminada, contrapondo a utilização em lugares onde haja agentes dispersores como o vento e as correntes marinhas (MROZIK e PIOTROWSKASEGET, 2010). Uma das estratégias para acelerar o processo de degradação de contaminantes hidrofóbicos consiste na aplicação de compostos que solubilizem esses poluentes, facilitando o acesso dos micro-organismos aos óleos e hidrocarbonetos emulsificados, intensificando o processo de degradação. Esses bioprodutos são denominados de biossurfactantes: os biorremediadores do petróleo (RUTA e JUOZAS, 2013).

O crescimento do Estado de Pernambuco tende a ascender pela alta capacidade de geração de renda, beneficiando a vários cidadãos. O lucro se consolida principalmente pelo desenvolvimento do Polo Petroquímico de Suape, detentor de várias indústrias, das quais, muitas utilizam o petróleo como matéria-prima. Essa mistura de óleos e hidrocarbonetos, todavia, é usualmente transportada por navios com a possibilidade de causar derramamentos, prejudicando a vida marinha, as populações ribeirinhas e outras empresas nas proximidades. A Termoelétrica de Pernambuco (TERMOPE) é uma das indústrias preocupadas com esse possível desastre ambiental e econômico, devido à possível captação da água contaminada com petróleo no sistema de arrefecimento dos geradores da empresa. Logo, a utilização de biossurfactantes é uma solução plausível para remediar esses acidentes petrolíferos.

Um produto microbiológico, para ser comercializado, necessita apresentar cinco fatores principais: baixa toxicidade, elevada biodegradabilidade, mínimos custos de produção, competitivos rendimentos com os existentes no mercado e eficientes e estáveis propriedades físico-químicas. As duas primeiras características aplicam-se aos biossurfactantes, pois contrapõem a contaminação acumulativa dos dispersantes químicos em ambientes marinhos (ROCHA E SILVA et al., 2014). A biotecnologia deve empregar também gastos reduzidos mediante a utilização de substratos provenientes de subprodutos industriais, sendo degradados por micro-organismos como leveduras, fungos filamentosos e bactérias (SANTOS et al., 2013). Os biossurfactantes produzidos por esses seres vivos devem apresentar um melhor custo-benefício comparado aos detergentes químicos, necessitando da extração do bioproduto em grandes quantidades e da aplicação eficiente baseada nas propriedades tensoativas. Logo, quando um surfactante microbiano consegue ser sintetizado com essas cinco características, há a possibilidade de utilizá-lo como um agente biorremediador.

Por ser produzido no meio líquido, o biossurfactante possui uma propriedade fundamental exemplificada por alguns insetos não submergirem quando estão em contato com a superfície aquosa. A razão citada se explica por existir um limite por forças repulsivas entre diferentes meios como a água e o ar cuja separação é bem definida visualmente nas regiões periféricas dessas substâncias. Essas tensões denominadas de superficiais, quando baixas, possibilitam o surfactante microbiano a se espalhar e dispersar meios apolares como o petróleo com grande facilidade, garantindo maior área de contato para posterior sucção ao ser aplicado. Ademais, outras peculiaridades sintomáticas dos biossurfactantes são influenciadas pela tensão superficial como emulsão, detergência, formação de micelas e solubilidade. Essas características consolidam a capacidade da dispersão de óleos em biossurfactantes e os ratificam como produtos biotecnológicos essenciais no controle dos desastres 


\section{9 a 22 de outubro de 2014 \\ Florianópolis/SC}

petrolíferos (RUFINO et al., 2013).

$\mathrm{O}$ estudo visou fazer uma analogia entre as melhores condições de estabilidade com o conservante sorbato de potássio a $0,2 \%$ nos biossurfactantes produzidos por Candida sphaerica e Candida lipolytica para selecionar após $120 \mathrm{~d}$ qual biotensoativo apresentava as maiores e mais constantes propriedades. Nesse trabalho, foram verificadas a tensão superficial e os índices de emulsificação e dispersão para as condições de $\mathrm{pH}$, salinidade e aquecimento em cada período de análise para escolher qual seria o surfactante microbiano indicado para uma biorremediação.

\section{MATERIAL E MÉTODOS}

\subsection{Micro-organismos e Substratos}

As leveduras Candida sphaerica (UCP0995) e Candida lipolytica (UCP0988), depositadas no Banco de Culturas do Núcleo de Pesquisas Ambientais da Universidade Católica de Pernambuco foram utilizadas como produtoras dos biossurfactantes. A repicagem desses organismos microbianos isolados ocorreu a cada $30 \mathrm{~d}$ para tubos de ensaio contendo o meio sólido de Yeast Mold Agar (YMA).

\subsection{Meios de Manutenção, de Crescimento dos Inóculos e de Produção dos Biossurfactantes}

As leveduras foram mantidas através da mistura sólida de YMA, composta por: extrato de malte $(0,3 \%)$, extrato de levedura $(0,3 \%)$, D-glicose $(1,0 \%)$, triptona ( $0,5 \%)$, ágar bacteriano $(2,0 \%)$ e água destilada q.s.p. $(100 \mathrm{~mL})$. Os componentes foram esterilizados em autoclave a $121^{\circ} \mathrm{C}$ por $20 \mathrm{~min}$. A exclusão do ágar propicia à mistura o estado líquido e é denominada de Yeast Mold Broth (YMB), indicando o meio de crescimento das leveduras. O meio de produção foi composto, para a levedura $C$. sphaerica, pelo acréscimo de $2,50 \%$ de milhocina e $5,00 \%$ de resíduo de óleo de soja do volume inicial, o pH foi ajustado para 5,5 e todo o meio foi autoclavado a $121{ }^{\circ} \mathrm{C}$ por 20 min. Enquanto que, para a levedura $C$. lipolytica, o meio de produção foi de $6,00 \%$ de resíduo de óleo de soja, $1,00 \%$ de ácido glutâmico, $0,10 \%$ de nitrato de amônia, $0,02 \%$ de fosfato monopotássico e $0,02 \%$ de sulfato de magnésio heptahidratado (RUFINO et al., 2014).

\subsection{Preparação dos Inóculos}

O inóculo tornou-se padrão pela transferência das leveduras para um tubo de ensaio, contendo o meio YMA, com a finalidade de se obter culturas jovens, em temperatura ambiente $\left(25^{\circ} \mathrm{C}\right)$. Logo após, as leveduras foram transferidas separadamente até frascos com YMB estéril. Por fim, os Erlenmeyers do YMB foram postos à agitação na máquina incubadora shaker durante $24 \mathrm{~h}$, a $200 \mathrm{rpm}$ e a $28^{\circ} \mathrm{C}$.

\subsection{Produção dos Biossurfactantes}

Para a produção dos biossurfactantes em shaker, após o crescimento dos inóculos em meio 
YMB, foram realizadas diluições seriadas para a contagem das células por mililitro e calculados o volumes para alcançar a concentração de $10^{4}$ células $/ \mathrm{mL}$ para Candida sphaerica e $1,0 \%$ do préinóculo da Candida lipolytica. Esses volumes determinados foram inseridos em frascos de Erlenmeyer com 2,0 L de capacidade volumétrica, contendo os respectivos meios de produção estéreis. As condições de manutenção em shaker foram: para a Candida sphaerica, agitação de 150 $\mathrm{rpm}$, na temperatura de $28{ }^{\circ} \mathrm{C}$ e durante $144 \mathrm{~h}$ e para a Candida lipolytica, agitação de $200 \mathrm{rpm}$, na temperatura de $28{ }^{\circ} \mathrm{C}$ e durante $72 \mathrm{~h}$.

\subsection{Determinação das Propriedades Surfactantes}

Os líquidos metabólicos obtidos pela shaker foram centrifugados a $4500 \mathrm{rpm}$ durante $15 \mathrm{~min}$, filtrados à vácuo e submetidos ao processo de extração. Os biossurfactantes passaram também pela filtração simples para a retirada dos resquícios de células.

As tensões superficiais foram medidas pelo método do anel DU NUOY no tensiômetro KSV Sigma 70 (Finland), determinando-se a força limite $(\mathrm{mN} / \mathrm{m})$ para suspender o anel de platina sobre o líquido metabólico livre de células até a interface ar-líquido.

Para a determinação das emulsões, foram colocados em tubos de ensaio, $2 \mathrm{~mL}$ dos biossurfactantes acoplados isovolumetricamente a três compostos apolares: óleos motor, de milho e de soja a $25^{\circ} \mathrm{C}$ e $1 \mathrm{~atm}$. Esses recipientes foram agitados em vórtex durante 2 min e deixados, durante $24 \mathrm{~h}$, em repouso. O índice de emulsificação foi calculado pela razão entre a altura da emulsão, visualizada na figura 1, e a altura total da mistura, sendo o valor multiplicado por 100 (COOPER e GOLDENBERG, 1987).

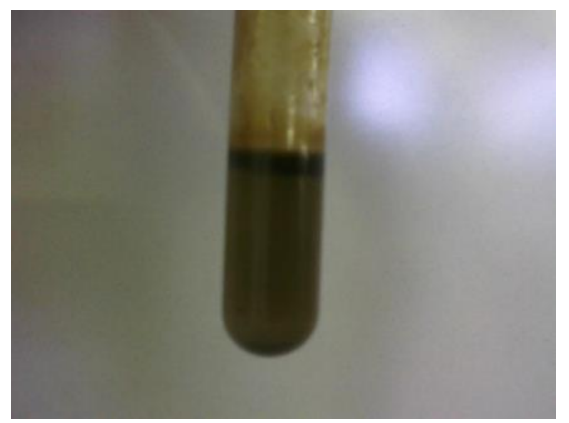

Figura 1 - Emulsão realizada com $2 \mathrm{~mL}$ de surfactante com $2 \mathrm{~mL}$ de óleo motor.

A capacidade de dispersão do óleo motor, conforme a figura 2, foi simulada em placa de Petri (14 cm de diâmetro), contendo $100 \mathrm{~mL}$ da água do mar, coletada nas proximidades do sistema de captação do gerador de energia da Termelétrica de Pernambuco. Uma quantidade desse óleo foi colocada no centro da placa, adicionando posteriormente diferentes proporções (v/v) dos surfactantes microbianos: 1:1, 1:2 e 1:8 (biossurfactante/óleo motor). Os valores foram medidos pela percentagem do diâmetro do halo, formado com a adição dos biossurfactantes, pelo da placa. (MORIKAWA et al., 2000). 


\section{9 a 22 de outubro de 2014 \\ Florianópolis/SC}

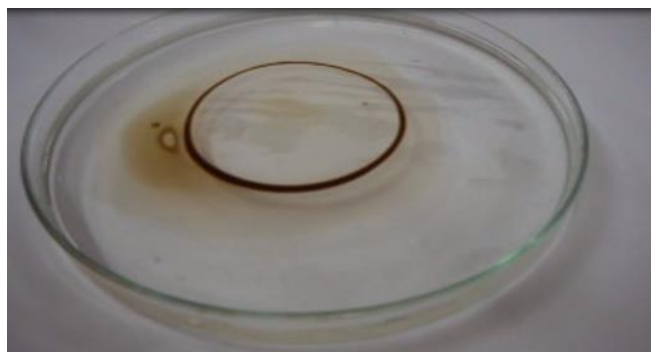

Figura 2 - Dispersão realizada em proporção 1:2 entre um biossurfactante e o óleo motor, respectivamente.

\subsection{Estabilização dos Biotensoativos}

A estabilização dos surfactantes microbianos ocorreu quando $0,2 \%$ do sal sorbato de potássio foi adicionado ao líquido metabólico livre de células, sendo dividido em vidros de armazenamento, em triplicata, para a verificação das propriedades surfactantes nos períodos de $0,15,30,45,90$ e 120 d. Em cada um desses dias, foram alteradas as condições de potencial hidrogeniônico para 5,7 e 9; adicionadas percentagens de $\mathrm{NaCl}$ a 1,3 e $5 \%$ do volume a ser estudado e aquecidas as amostras durante $30 \mathrm{~min}$ a 40 e $50{ }^{\circ} \mathrm{C}$. Para avaliar as propriedades surfactantes, foram selecionadas as melhores condições nas tensões superficiais e nos índices de emulsificação e de dispersão. Após a seleção, foram comparadas as características tensoativas para se determinar qual melhor surfactante microbiano deve ser utilizado em um derramamento marinho.

\section{RESULTADOS E DISCUSSÕES}

\subsection{Estabilidade dos Biossurfactantes pela Tensão Superficial}

As melhores condições para o biodetergente da Candida sphaerica foram $\mathrm{pH} 5$, salinidade $3 \% \mathrm{e}$ aquecimento a $40{ }^{\circ} \mathrm{C}$; enquanto que para o surfactante microbiano de Candida lipolytica as condições mais adequadas foram $\mathrm{pH} 9$, salinidade $5 \%$ e aquecimento a $40{ }^{\circ} \mathrm{C}$. Os experimentos seguiram-se, então, pela comparação entre os dois biossurfactantes durante $120 \mathrm{~d}$.

Nos gráficos de estabilidade, as propriedades surfactantes estão mensuradas pelas colunas para o biossurfactante sintetizado por $C$. sphaerica e as linhas para o biotensoativo produzido por $C$. lipolytica. A partir da primeira analogia entre os surfactantes microbianos sintetizados por $C$. sphaerica e $C$. lipolytica, observada na figura 3 , evidenciaram-se as melhores forças repulsivas, no tensoativo produzido pela primeira espécie de Candida descrita, como a menor tensão superficial de $22,45 \mathrm{mN} / \mathrm{m}$ nos $30 \mathrm{~d}$ de experimento. Além das baixas tensões, a uniformidade é outro fator a ser destacado pelo biocomposto da $C$. sphaerica, o qual apresentou um pequeno desvio padrão obtido em pH 5 de $0,69 \mathrm{mN} / \mathrm{m}$, quando comparado com o desvio padrão do biodetergente da levedura $C$. lipolytica com um valor 4,45 vezes maior. Neste biotensoativo, percebem-se, pois, não apenas elevadas variâncias de medidas, outrossim, picos extremos de tensões como no controle e em pH 9 com 36,50 e $36,90 \mathrm{mN} / \mathrm{m}$, respectivamente. Porquanto, no aspecto de baixas tensões superficiais, o bioproduto da levedura $C$. sphaerica foi o mais eficiente, favorecendo um potencial contato com óleos no caso de derramamentos e sendo possível armazená-lo durante um longo período, com 


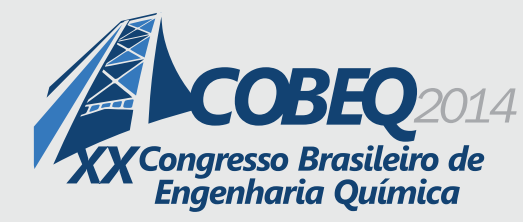

19 a 22 de outubro de 2014

Florianópolis/SC

estabilidade e nas condições do ambiente.

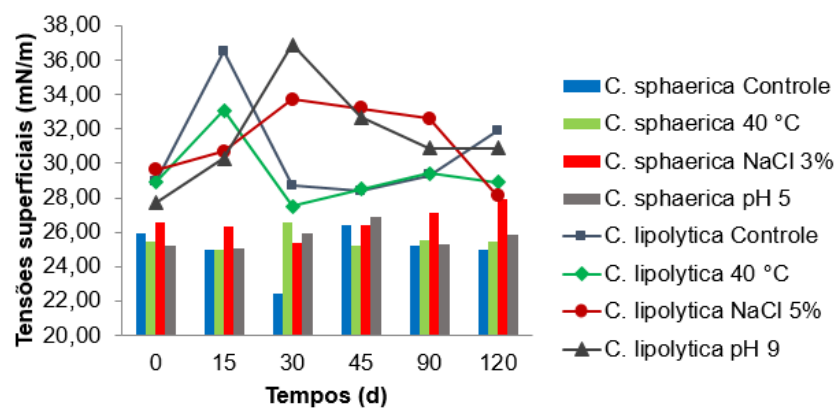

Figura 3 - Comparação das tensões superficiais entre os biossurfactantes de Candida sphaerica e Candida lipolytica com sorbato de potássio a $0,2 \%$, durante $120 \mathrm{~d}$, sob variação de $\mathrm{pH}, \mathrm{NaCl}$, aquecimento e com o controle das condições.

\subsection{Estabilidade dos Biossurfactantes pelo Índice de Emulsificação}

Assim como verificado por Ferreira et al. (2013) com um biossurfactante produzido pela bactéria Pseudomonas sp. em resíduos industriais, as emulsões em óleo motor, na figura 4-A, atingiram índices de cerca de $90,0 \%$ para o biossurfactante sintetizado pela $C$. sphaerica cuja medida máxima foi de $94,1 \%$ aos 45 d com um prévio aquecimento na temperatura de $40{ }^{\circ} \mathrm{C}$. A regularidade pelo baixo desvio padrão de 4,4\% foi notável nesse aquecimento, distinguindo-se do desvio de $31,2 \%$ encontrado no biotensoativo produzido pela $C$. lipolytica. Esses resultados corroboram com o estudo da tensão superficial, indicando o biossurfactante da levedura $C$. sphaerica como um melhor agente emulsificante de óleo motor perante o obtido pela $C$. lipolytica.
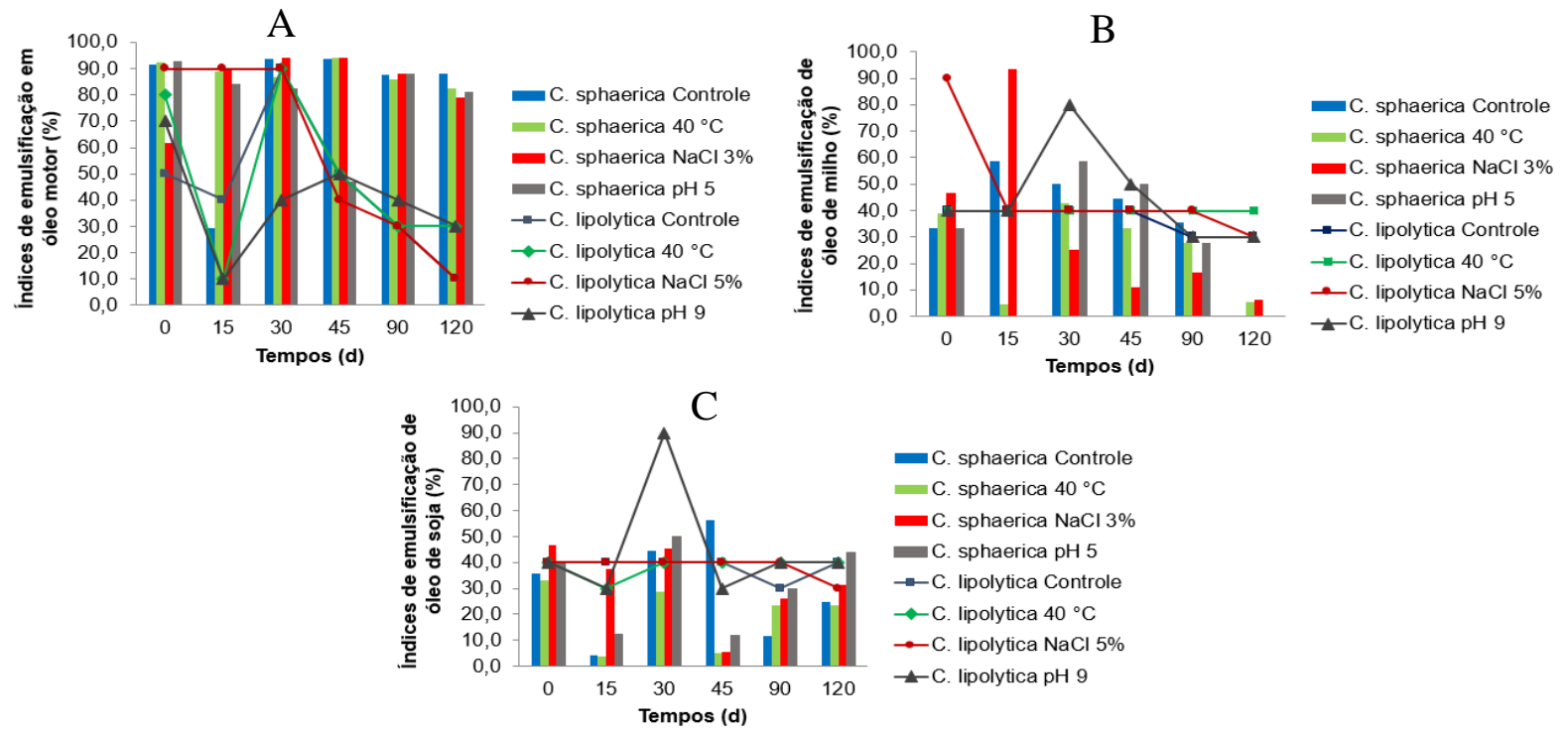

Figura 4 - Comparação das emulsificações em óleos motor (A), de milho (B) e de soja (C) entre os biossurfactantes de Candida sphaerica e Candida lipolytica com sorbato de potássio a 0,2\%, durante 120 d, sob variação de $\mathrm{pH}, \mathrm{NaCl}$, aquecimento e com o controle das condições. 


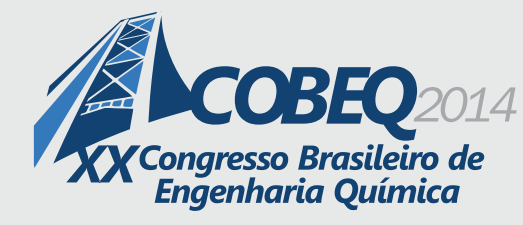

19 a 22 de outubro de 2014
Florianópolis/SC

Severas distinções nas emulsificações dos surfactantes microbianos foram evidenciadas nas figuras 4-B e 4-C, nos óleos vegetais de milho e de soja, respectivamente. Nos dois óleos, o biossurfactante produzido por $C$. lipolytica obteve melhores resultados com médias 46,7 e 38,3\%, na salinidade de $5 \%$ e na similar ordem descrita dos óleos. Por outro lado as inconstantes medidas e os elevados desvios padrões, tornam o uso destes tensoativos como pouco impactantes e imprecisos para aplicações em óleos vegetais, voltando-se o uso para derramamentos de petróleo.

\subsection{Estabilidade dos Biossurfactantes pelo Índice de Dispersão}

As dispersões 1:2 do biossurfactante produzido por $C$. sphaerica também foram superiores, alcançando percentagens máximas de $73,3 \%$ aos $30 \mathrm{~d}$ de experimento e em $\mathrm{pH} 5$, na figura 5-A. $\mathrm{O}$ tensoativo sintetizado por $C$. lipolytica obteve, todavia, propriedades em média de 15,0\% na semelhante proporção entre o biossurfactante e o óleo motor. Essa razão, conforme é reduzida pelo aumento da quantidade de óleo, nas figuras 5-B e 5-C, mantém a equivalência das propriedades, com dispersões de 70,0\% para as semelhantes condições de 73,3\%, e apresenta baixos desvios, menores que $13,0 \%$, nos dois surfactantes. A partir desses resultados, fica evidentemente descartado, para a remediação de derramamentos petrolíferos, o uso do tensoativo de $C$. lipolytica diante do biodetergente de $C$. sphaerica, mantidos por sorbato de potássio.
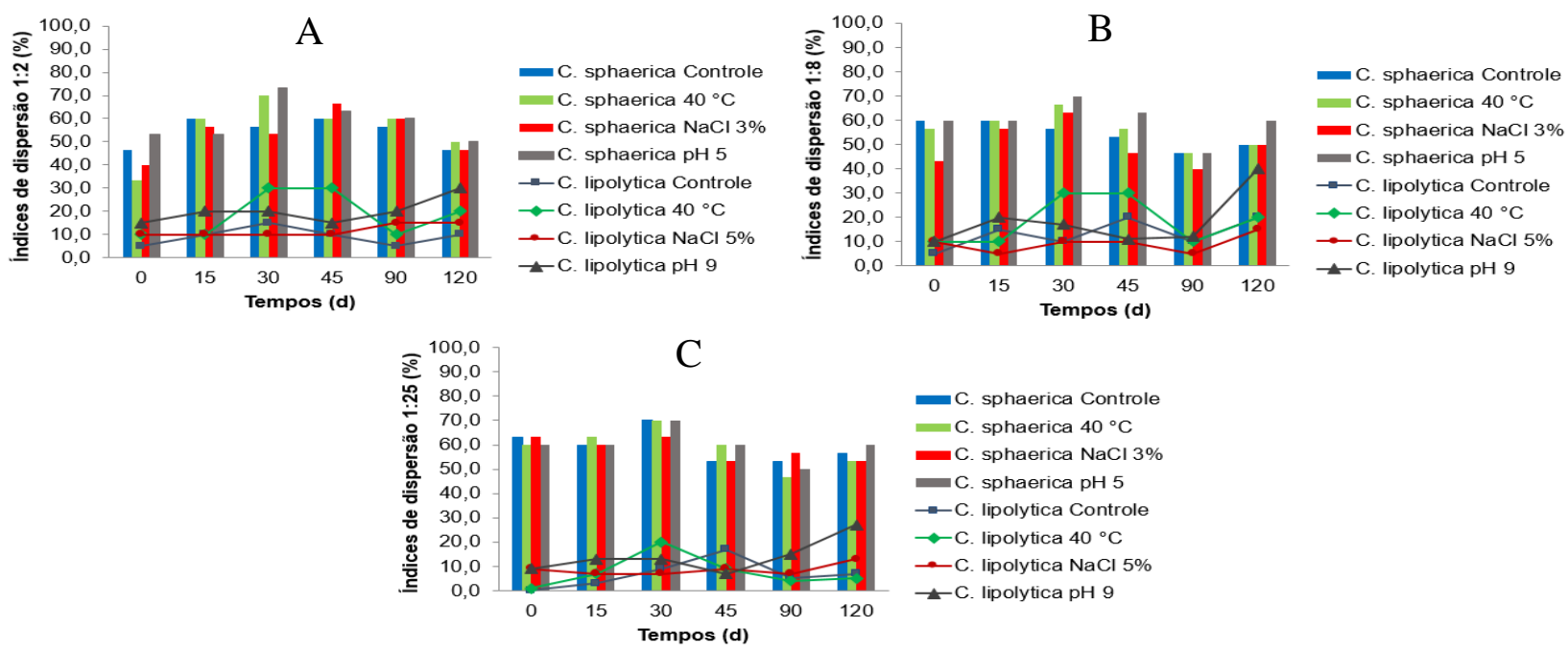

Figura 5 - Comparação das dispersões em proporções 1:2 (A), 1:8 (B) e 1:25 (C) entre os biossurfactantes de Candida sphaerica e Candida lipolytica com sorbato de potássio a 0,2\%, durante 120 d, sob variação de $\mathrm{pH}, \mathrm{NaCl}$, aquecimento e com o controle das condições.

\section{CONCLUSÕES}

O biossurfactante produzido por Candida sphaerica apresentou melhores propriedades de tensão superficial e de índices de emulsão de óleo motor e de dispersão, sendo, logo, um excelente biorremediador para possíveis desastres ambientais como o ocorrido no Golfo do México, em 2010. Enquanto que o tensoativo sintetizado pela levedura Candida lipolytica apenas demonstrou uma melhor qualidade na redução das forças repulsivas em óleos vegetais. 
É interessante o estudo de diversos micro-organismos com potencial biotecnológico para aplicação na síntese de compostos biorremediadores, pois pode-se prever qual biossurfactante terá as melhores propriedades sob $\mathrm{pH}$, salinidade ou aquecimento diferentes. Deve-se, porém, salientar que essas condições foram mensuradas separadamente, necessitando de um arranjo simples com a mescla das condições para definir-se o sinergismo ou o antagonismo e utilizar o surfactante correto no momento de um derramamento de óleo no mar.

\section{REFERENCIAS}

COOPER, D. G.; GOLDENBERG, B. G. Surface-Active Agents from two Bacillus Species. Appl. Environ. Microbiol., v. 53, p. 224-229, 1987.

FERREIRA, I. N.; BRASILEIRO, P. P. F.; RUFINO, R. D.; LUNA, J. M.; SARUBBO, L. A. Biossurfactante DE Pseudomonas sp. conservado por sorbato de potássio. In: VI SIMPÓSIO DE CIÊNCIAS BIOLÓGICAS, CD-ROM, v. 1, p. 89-96, 2013.

MORIKAWA, M.; HIRATA, Y.; IMANAKA, T. A study on the structure-function relationship of lipopeptide biosurfactants. Biochim. Biophys. Acta, v. 1488, p. 211-218, 2000.

MROZIK, A.; PIOTROWSKA-SEGET, Z. Bioaugmentation as a strategy for cleaning up of soils contaminated with aromatic compounds. Microbiol. Research, v. 165, p. 363-375, 2010.

ROCHA e SILVA, N. M. P.; RUFINO, R. D.; LUNA, J. M.; SANTOS, V. A.; SARUBBO, L. A. Screening of Pseudomonas species for biosurfactant production using low-cost substrates. Biocatal. Agric. Biotechnol., v. 3, p. 132-139, 2014.

TANSEL, B. Propagation of impacts after oil spills at sea: Categorization and quantification of local vs regional and immediate vs delayed impacts. Int. J. Disaster Risk Reduct., v. 7, p. 1-8, 2014.

RUFINO, R. D.; LUNA, J. M.; CAMPOS TAKAKI, G. M.; SARUBBO, L. A. Characterization and properties of the biosurfactant produced by Candida lipolytica UCP 0988. Electron. J. Biotechno., v. 17, p. 34-38, 2014.

RUFINO, R. D.; LUNA, J. M.; MARINHO, P. H. C.; FARIAS, C. B. B.; FERREIRA, S. R. M.; SARUBBO, L. A. Removal of petroleum derivative adsorbed to soil by biosurfactant Rufisan produced by Candida lipolytica. J. Petrol. Sci. Eng., v. 109, p. 117-202, 2013.

RUTA, I-G. e JUOZAS, K. Effects of rhamnolipid biosurfactant JBR425 and synthetic surfactant Surfynol465 on the peroxidase-catalyzed oxidation of 2-naphthol. J. Environ. Sci., v. 25, p. 1431-1440, 2013.

SANTOS, D. K. F.; RUFINO, R. D.; LUNA, J. M.; SANTOS, V. A.; SALGUEIRO, A. A.; SARUBBO, L. A. Synthesis and evaluation of biosurfactant produced by Candida lipolytica using animal fat and corn steep liquor. J. Petrol. Sci. Eng., v. 105, p. 43-50, 2013. 